\title{
Treatment of atlantoaxial dislocations among patients with cervical osseous or vascular abnormalities utilizing hybrid techniques
}

\author{
Shenglin Wang, MD, ${ }^{1}$ Yinglun Tian, MD, ${ }^{1}$ Bassel G. Diebo, MD, ${ }^{2}$ Samantha R. Horn, $B A,{ }^{3}$ and \\ Peter G. Passias, MD³ \\ ${ }^{1}$ Orthopaedic Department, Peking University Third Hospital, Beijing, China; ${ }^{2}$ State University of New York, Downstate Medical \\ Center, Brooklyn, New York; and ${ }^{3} \mathrm{NYU}$ Hospital for Joint Diseases, New York, New York
}

\begin{abstract}
OBJECTIVE Most cervical fixations for atlantoaxial dislocation (AAD) are bilateral and symmetric; however, in the setting of osseous and vascular deformity at the craniovertebral junction, asymmetrical and hybrid fixations are used as "salvage" techniques. Because of the rarity of these cases, hybrid cervical fixations for AAD have not been fully explored. The aim of this study was to evaluate the clinical feasibility and outcomes of posterior hybrid cervical fixations for AAD.

METHODS Twenty-one AAD cases were retrospectively studied; 18 had cervical myelopathy with Japanese Orthopaedic Association (JOA) scores ranging from 9 to 16 (mean 13.5). Hybrid fixation techniques included unilateral pedicle screws, transarticular screws, C-2 laminar screws, cervical lateral mass screws, and spinous process screws. During the same period, 82 AAD cases, treated using symmetric traditional fixations, were analyzed as controls.

RESULTS Atlantoaxial fixation was performed in 11 cases, while occiput-cervical fixation was used in 10 cases. All cases achieved solid osseous fusion. Anatomical reduction was achieved in 20 cases (95.2\%). All 18 cases with myelopathy showed postoperative improvement, with JOA scores ranging from 13 to 17 (mean 15.5). Three cases (14.2\%) experienced complications, including delayed wound healing, CSF leakage, and fixation loosening. Hybrid fixation techniques showed significantly greater estimated blood loss when compared with controls $(208.1 \pm 19.30 \mathrm{ml}$ vs $139.63 \pm 8.75 \mathrm{ml}, \mathrm{p}$ $=0.001)$. Operative duration (125.38 \pm 6.29 min vs $119.41 \pm 3.77 \mathrm{~min}, p=0.464)$, complication rates $(14.3 \%$ vs $4.9 \%, p=$ $0.148)$, and JOA improvement rates $(61 \% \pm 7 \%$ vs $49 \% \pm 4 \%, p=0.161)$ showed no significant differences.
\end{abstract}

CONCLUSIONS For ADD with osseous or vascular deformity, posterior cervical reduction and stabilization can be achieved using hybrid techniques, resulting in comparable clinical results to symmetric traditional fixation.

https://thejns.org/doi/abs/10.3171/2017.12.SPINE17632

KEYWORDS atlantoaxial dislocation; osseous deformity; vascular deformity; craniovertebral junction; hybrid fixations; asymmetric fixation; C-2 laminar screw; cervical pedicle screw; spinous process screw; myelopathy; surgical technique

$\mathrm{C}$ ONDITIONS resulting in atlantoaxial dislocations (AADs) are rare but have the potential for severe consequences of neurological deterioration, such as myelopathy, paralysis, respiratory failure, or even death..$^{8,20}$ AAD typically requires surgical treatment with several atlantoaxial fixation and fusion methods..$^{18,20}$ The available techniques of posterior atlantoaxial instrumentation include pedicle screw (PS) fixation at C-2, C-1 and C-2 transarticular screws (TASs), C-2 laminar screws (LSs), and lateral mass screws (LMSs) at C-1, among others. ${ }^{20}$ The connection in fixation methods can be achieved using two general methods: rod or plate designs., ${ }^{4,5}$ Cervical fixation methods are often bilateral and symmetric; however, concomitant osseous or vascular deformities at the cra-

ABBREVIATIONS $A A D=$ atlantoaxial dislocation; $A D I=$ atlantodental interval; JOA = Japanese Orthopaedic Association; KFS $=$ Klippel-Feil syndrome; $L M S=$ lateral mass screw; LS = laminar screw; PS = pedicle screw; SPS = spinous process screw; TAS = transarticular screw; VA = vertebral artery; VAS = visual analog scale. SUBMITTED June 9, 2017. ACCEPTED December 12, 2017.

INCLUDE WHEN CITING Published online May 11, 2018; DOI: 10.3171/2017.12.SPINE17632. 
niovertebral junction prohibit symmetrical fixation techniques. Thus, asymmetrical hybrid fixations are frequently used as "salvage" procedures.9,14

Several authors previously reported on alternative or salvage C-2 LS placement in lieu of traditional fixation techniques, such as PS fixation, ${ }^{2,6}$ because of the rarity of these cases, the feasibility and results of salvage hybrid cervical fixations for AADs have not been fully explored. In the current series, the clinical features, treatment pitfalls, and surgical outcomes of 21 cases are investigated.

\section{Methods}

\section{Study Design and Clinical Features}

This study was a retrospective review of a prospectively collected database. IRB approval from Peking University Third Hospital and informed patient consent were obtained prior to study enrollment. One hundred and three patients with AAD were treated surgically by the senior author (S.W.) from September 2008 to September 2013. The sole criteria for the presence of AAD was an atlantodental interval (ADI) greater than $3 \mathrm{~mm}$; for patients younger than 18 years of age, greater than $5 \mathrm{~mm}$ was used. Among these 103 AAD cases, 21 patients with upper cervical osseous or vascular deformities underwent surgical reduction and fixation utilizing hybrid atlantoaxial fixations. Hybrid fixation was defined as the use of two or more asymmetrical fixation techniques. Analysis was retrospectively performed in this series. The mean followup duration was 45.0 months (range 36-60 months). There were 14 females and 7 males included. The ages ranged from 7 to 71 years, with a mean of 44.2 years. Fourteen cases were classified as reducible AAD, while 7 were determined to be fixed AADs. Eighteen cases had myelopathy on presentation (Japanese Orthopaedic Association [JOA] score range 9-16, mean 13.5). Prior to surgical correction, the patients underwent dynamic lateral radiographs, as well as reconstructive CT and MR imaging of the cervical spine. Among the 21 cases, 9 had evidence of occipitalization of the atlas, 6 had Klippel-Feil syndrome (KFS) with C-2 and C-3 congenital fusions, and 1 had a $\mathrm{C}-2$ to $\mathrm{C}-6$ congenital fusion (KFS). Four cases had tonsillar herniations (Chiari malformation type I deformities) and 3 had syringomyelia. Further details of radiographic findings and clinical data are presented in Table 1 . The other 82 cases with symmetric traditional fixations were analyzed as the control group. The control cases underwent surgery by the same surgeon, and the intraoperative and postoperative procedures (except for the fixation techniques) were kept consistent with the "hybrid" cases.

\section{Surgical Methods}

Instrumentation and Fusion Length (fixed and fused segmentation)

To preserve cervical mobility, the shortest instrumentation length was preferred; thus, atlantoaxial fixation was always the first option. In hypoplasia or occipitalization of the atlas, fixation extending from the occiput to C-2 was used. In KFS cases, the fixation was typically extended only to the congenital fused segments, without further sacrificing the lower cervical movements.

\section{Determination of Initial Technique and Salvage Procedures}

C-1 and C-2 PSs or TASs were always the initial option for fixation, because of the solid biomechanical features. In the setting of a "high-riding" vertebral artery (VA) at C-2, or C-2 PS insertion failure, C-2 LSs were chosen. For patients with KFS, the fixation was extended to the subaxial spine, preferably with cervical PS placement at these caudal levels. LMSs were used alternatively for lower cervical pedicle hypogenesis. We found that connecting C-2 LSs with lower LMSs was challenging and required acute rod angulation. To strengthen C-2 LSs in KFS, cervical spinous process screws (SPSs) were used. Only cases undergoing asymmetrical fixations were retrospectively analyzed.

Lateral Mass, PS, and Plate Fixation of $C-1$ and $C-2$. The C-1 (usual diameter $3.5 \mathrm{~mm}$, length $30 \mathrm{~mm}$ ) and C-2 PS (diameter $3.5 \mathrm{~mm}$, length $26-28 \mathrm{~mm}$ ) was inserted, followed by placement of the reconstruction plate between $\mathrm{C}-1$ and C-2 (Fig. 1).

Transarticular Cl-2 Fixation (modified Magerl's technique without the cable). A 3.5-mm full-threaded cortical titanium screw (length $38-42 \mathrm{~mm}$ ) was inserted across the $\mathrm{C} 1-\mathrm{C} 2$ lateral mass joint. We did not use cable in this study. ${ }^{15}$

Occiput to C-2 Fixation Using C-2 PSs. Patients with occipitalization of the atlas or dysplasia of the C-1 posterior arch underwent this technique. C-2 PSs were placed as previously described. The occiput and C-2 were connected by a reconstruction plate. Three $3.5-\mathrm{mm}$ bicortical screws were placed into the occiput.

Cl-2 or Occiput to C-2 Fixation Using C-2 LSs. Among patients with VAs that were high-riding (Fig. 1) or in patients with osseous anomalies of the $\mathrm{C}-2$ pedicle, C-2 LSs were used as a salvage technique for C1-2 stabilization, or in select cases of occipitocervical fixation. The procedure used the technique of Wright. ${ }^{19}$ The LS was connected with $\mathrm{C}-1$ or occipital screws using a titanium rod (Fig. 1).

Cervical LMS. In KFS cases, the lower cervical LMSs (diameter $3.5 \mathrm{~mm}$, length $12-16 \mathrm{~mm}$ ) were connected with a C-2 PS, strengthening the hybrid fixation.

Lower Cervical SPSS. An entry point was created with a burr at the bottom of the spinous process. The screw trajectory was drilled toward the contralateral laminar surface and penetrated out from the junction of the lamina and the spinous process, and without penetrating into the lamina. After checking and tapping, the screws were fixed on the spinous process bicortically. The length of the SPSs in this report ranged from 12 to $14 \mathrm{~mm}$. Then the screws were connected with the C-2 LSs with rods.

\section{Procedures After Fixation}

At the end of the procedure, for all 103 cases, the C-1 arch, C-2 lamina, and spinous process were decorticated with a high-speed burr. Morselized cancellous grafts harvested from the posterior iliac crest were bridged between the C-1 arch and C-2 lamina. For 100 cases, no brace was used postoperatively. However, in 3 "hybrid" cases, severe dislocation and viscoelastic rebound forces were 
TABLE 1. Clinical data of 21 cases

\begin{tabular}{|c|c|c|c|c|c|}
\hline $\begin{array}{l}\text { Case } \\
\text { No. }\end{array}$ & $\begin{array}{l}\text { Age } \\
\text { (yrs), } \\
\text { Sex }\end{array}$ & Diagnosis & $\begin{array}{c}\text { Hybrid Categories \& Fixation } \\
\text { Segments }\end{array}$ & $\begin{array}{c}\text { Reasons for Using Salvage } \\
\text { Techniques }\end{array}$ & Complications \\
\hline 1 & $52, \mathrm{M}$ & Reducible AAD, O०, myelopathy & 2 (C-2 PS + C-2 LS), C1-2 fixation & High-riding VA at C-2 segment & $\begin{array}{l}\text { Iliac wound exudation \& } \\
\text { delayed healing }\end{array}$ \\
\hline 2 & $47, \mathrm{~F}$ & $\begin{array}{l}\text { Irreducible AAD, occipitalization, BI, } \\
\mathrm{TH} \text {, myelopathy }\end{array}$ & 2 (C-2 PS + C-2 LS), C1-2 fixation & High-riding VA at C-2 segment & NA \\
\hline 3 & $44, \mathrm{~F}$ & $\begin{array}{l}\text { Irreducible AAD, myelopathy, occipi- } \\
\text { talization, KFS (fused C2-3/C5-6) }\end{array}$ & $\begin{array}{l}2 \text { (C-2 PS + C-2 LS), Oc-C2 } \\
\text { fixation }\end{array}$ & $\begin{array}{l}\text { Blocked \& hypoplastic C-2 rt } \\
\text { pedicle in KFS case }\end{array}$ & NA \\
\hline 4 & $58, \mathrm{M}$ & Reducible AAD, myelopathy & 2 (C-2 PS + C-2 LS), C1-2 fixation & High-riding VA at C-2 segment & NA \\
\hline 5 & $38, \mathrm{M}$ & Reducible AAD, 00 & 2 (C-2 PS + C-2 LS), C1-2 fixation & High-riding VA at C-2 segment & NA \\
\hline 6 & $39, \mathrm{~F}$ & Reducible AAD, OO, myelopathy & 2 (C-2 PS + C-2 LS), C1-2 fixation & High-riding VA at C-2 segment & NA \\
\hline 7 & $38, F$ & $\begin{array}{l}\text { Irreducible AAD, occipitalization, my- } \\
\text { elopathy, BI, hypoplastic laminae } \\
\text { of C-2 \& C-3 }\end{array}$ & $\begin{array}{l}2 \text { (C-2 PS + C-3 LS), Oc-C3 fixa- } \\
\quad \text { tion, \& halo vest for } 3 \text { mos }\end{array}$ & $\begin{array}{l}\text { Hypoplastic C-2 laminae w/ } \\
\text { hypotrophic pedicle of } \mathrm{C}-2 \\
\text { (rt side) }\end{array}$ & NA \\
\hline 8 & $31, F$ & $\begin{array}{l}\text { Irreducible AAD, myelopathy, BI, } \\
\text { KFS (fused C2-3) }\end{array}$ & 2 (C-2 PS + C-2 LS), C1-2 fixation & $\begin{array}{l}\text { Blocked \& hypoplastic C-2 It } \\
\text { pedicle in KFS case }\end{array}$ & NA \\
\hline 9 & $61, \mathrm{~F}$ & Irreducible AAD, O० & 2 (C-2 PS + C-2 LS), C1-2 fixation & High-riding VA at C-2 segment & NA \\
\hline 10 & $61, \mathrm{M}$ & $\begin{array}{l}\text { Reducible AAD, old odontoid frac- } \\
\text { ture, myelopathy }\end{array}$ & 2 (C-2 PS + C-2 LS), C1-2 fixation & High-riding VA at C-2 segment & NA \\
\hline 11 & $70, \mathrm{M}$ & $\begin{array}{l}\text { Reducible AAD, OO, myelopathy, } \\
\text { Kaschin-Beck disease }\end{array}$ & 2 (C-2 PS + C-2 LS), C1-2 fixation & High-riding VA at C-2 segment & NA \\
\hline 12 & $19, \mathrm{M}$ & $\begin{array}{l}\text { Irreducible AAD, occipitalization, } \\
\text { BI, myelopathy, syringomyelia, } \\
\text { torticollis }\end{array}$ & $\begin{array}{l}2 \text { (C-2 PS + C-2 LS), Oc-C2 fixa- } \\
\quad \text { tion, \& halo vest for } 4 \text { mos }\end{array}$ & $\begin{array}{l}\text { Blocked \& hypoplastic C-2 rt } \\
\text { pedicle in KFS case }\end{array}$ & $\begin{array}{l}\text { Screws loosening \& } \\
\text { dislocation recurred } \\
\text { at } 4 \text { mos postop, \& } \\
\text { performing transoral } \\
\text { revision }\end{array}$ \\
\hline 13 & $50, F$ & Reducible AAD, OO, myelopathy & 2 (C-2 PS + C-2 LS), C1-2 fixation & High-riding VA at C-2 segment & NA \\
\hline 14 & $12, \mathrm{~F}$ & $\begin{array}{l}\text { Irreducible AAD, myelopathy, BI, } \\
\text { occipitalization, KFS (fused C2-3), } \\
\text { TH, syringomyelia }\end{array}$ & $\begin{array}{l}2 \text { (C-2 PS + C-2 LS), Oc-C2 } \\
\quad \text { fixation }\end{array}$ & $\begin{array}{l}\text { Blocked \& hypoplastic C-2 rt } \\
\text { pedicle in KFS case }\end{array}$ & NA \\
\hline 15 & $7, \mathrm{M}$ & $\begin{array}{l}\text { Reducible AAD, myelopathy, verte- } \\
\text { bral hypogenesis of } C 2-6\end{array}$ & $\begin{array}{l}2 \text { (C-2 PS + C-2 LS), Oc-C2 fixa- } \\
\quad \text { tion, \& halo vest for } 3 \text { mos }\end{array}$ & $\begin{array}{c}\text { Vertebral hypogenesis of C2-6 } \\
\text { \& C-2 PS plantation failure }\end{array}$ & NA \\
\hline 16 & $71, \mathrm{~F}$ & $\begin{array}{l}\text { Reducible AAD, occipitalization, } \\
\text { myelopathy }\end{array}$ & $\begin{array}{l}2 \text { (C-2 PS + C-2 LS), Oc-C2 } \\
\quad \text { fixation }\end{array}$ & High-riding VA at C-2 segment & NA \\
\hline 17 & $17, \mathrm{~F}$ & $\begin{array}{l}\text { Reducible AAD, occipitalization, my- } \\
\text { elopathy, KFS (fused C2-3), TH }\end{array}$ & $\begin{array}{l}3 \text { (C-2 PS + C-2 LS + C-3 LMS) } \\
\quad \text { Oc-C3 fixation }\end{array}$ & $\begin{array}{l}\text { Blocked \& hypoplastic C-2 } \\
\text { pedicles in KFS case, \& high- } \\
\text { riding VA at C-2 segment }\end{array}$ & NA \\
\hline 18 & $56, \mathrm{~F}$ & Reducible AAD, OO & 2 (C-2 PS + C-2 LS), C1-2 fixation & High-riding VA at C-2 segment & NA \\
\hline 19 & $50, F$ & $\begin{array}{l}\text { Reducible AAD, occipitalization, KFS } \\
\text { (fused C2-3), myelopathy, swal- } \\
\text { lowing disturbance }\end{array}$ & $\begin{array}{c}4 \text { (C-2 PS + C-2 LS + C-3 LMS + } \\
\text { C-3 SPS), Oc-C3 fixation }\end{array}$ & $\begin{array}{l}\text { Blocked \& hypoplastic C-2 } \\
\text { pedicles in KFS case }\end{array}$ & $\begin{array}{l}\text { CSF leakage was treated } \\
\text { successfully by } \\
\text { prolonged drainage \& } \\
\text { pressure dressing }\end{array}$ \\
\hline 20 & $59, \mathrm{~F}$ & $\begin{array}{l}\text { Reducible AAD, C-1 hypogenesis, } \\
\text { KFS (fused C2-6), myelopathy }\end{array}$ & $\begin{array}{l}3 \text { (C-2 LS + C-2/3/6 LMS + C-3/5 } \\
\quad \text { SPS), Oc-C6 fixation }\end{array}$ & $\begin{array}{l}\text { Blocked \& hypoplastic C2-6 } \\
\text { pedicles in KFS case, \& C-1 } \\
\text { screw plantation failure }\end{array}$ & NA \\
\hline 21 & $49, \mathrm{~F}$ & $\begin{array}{l}\text { Reducible AAD, occipitalization, KFS } \\
\text { (fused C2-3), myelopathy, TH, sy- } \\
\text { ringomyelia, articulation disorder }\end{array}$ & $\begin{array}{l}3 \text { (TAS + C-2 PS + C-3 LMS), } \\
\text { Oc-C3 fixation }\end{array}$ & $\begin{array}{l}\text { Blocked \& hypoplastic C-2 } \\
\text { pedicles in KFS case (C-2 } \\
\text { PS partly cutting) }\end{array}$ & NA \\
\hline
\end{tabular}

$\mathrm{BI}=$ basilar invagination; $\mathrm{NA}=$ not applicable $\mathrm{OO}=0$ odontoideum; $\mathrm{TH}=$ tonsillar herniation . 


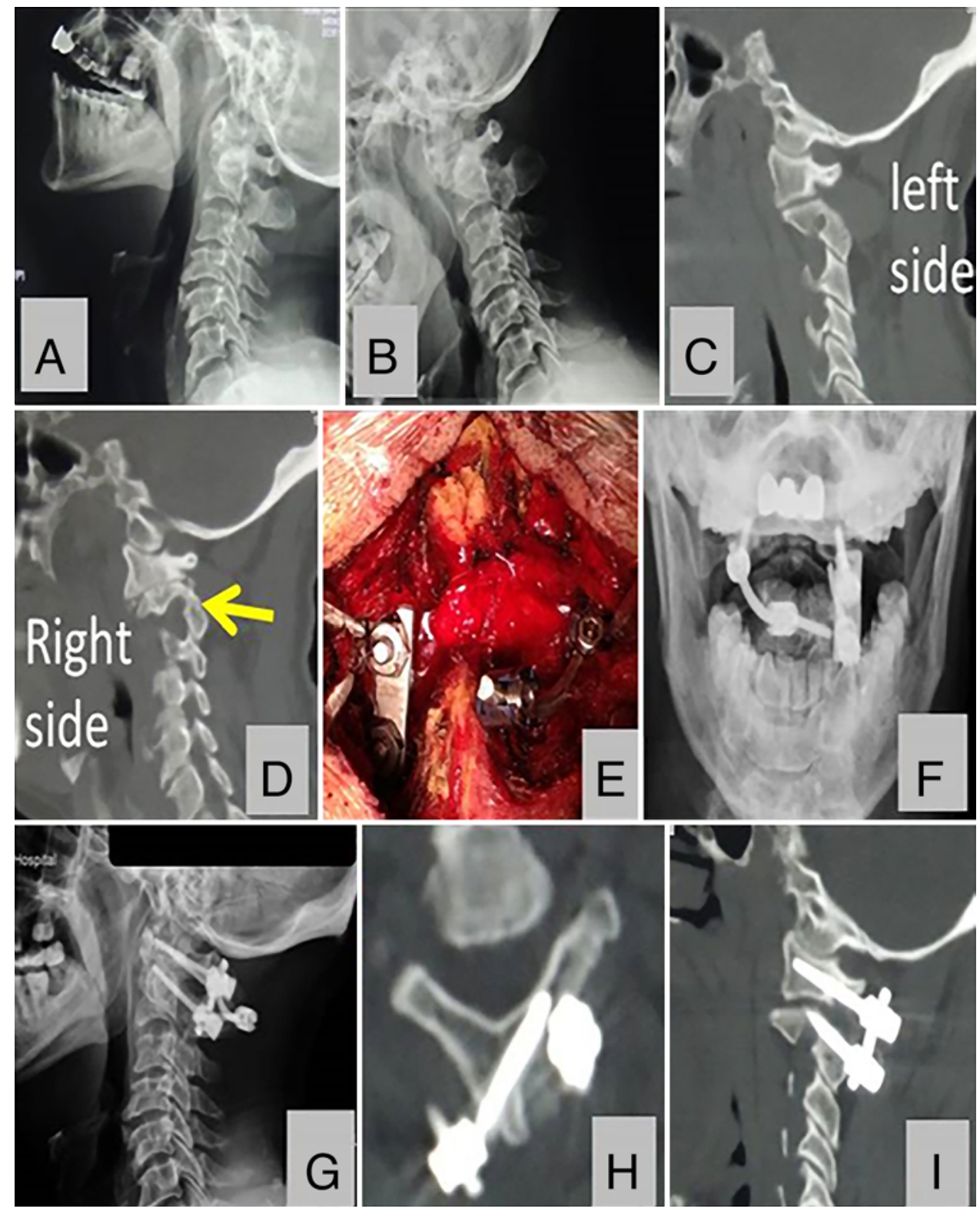

FIG. 1. Case 10. A 61-year-old man was diagnosed with $A A D$ (A and B) with myelopathy. Preoperative CT showed the left pedicle of $C$-2 was fine (C) but the right VA was high-riding and invaded the C-2 pedicle (D, arrow). The PSs and plate fixation were used on the left side, while the right side was fixed using C-1 PSs and C-2 LSs (E). Postoperative radiographs (F and G) and CT (H and I) revealed good position of the screws. The anatomical reduction was achieved. Figure is available in color online only.

noted during the procedure, and additionally a halo vest was used postoperatively for supplemental stability (for 4 months after the fusion was confirmed). Drains were removed at 48 hours. After these procedures, patients were mobilized out of bed and were encouraged to participate in basic physical therapy. All 103 patients underwent postoperative radiographs and reconstructive CT scans of the cervical spine at 5 days and 4 months after the surgery. Radiographic examination was repeated at 12 months and annually thereafter. Fusion and screw position were confirmed by postoperative reconstructive CT (if fusion could not be confirmed using 4-month CT, we repeated reconstructive CT scans after 3 months). We used the Tan et al. criteria ${ }^{12}$ for assessing fusion, documenting bridging osseous union between the proximal and distal end point, which was determined to be grade 1 . Density of volume of fusion was not assessed in this series.

\section{Results}

Among the 21 cases, 17 underwent posterior hybrid fixations using two distinct techniques, 3 used three techniques, while 1 case involved four distinct techniques. The reasons for hybrid fixations included: VA was high-riding at the C-2 segment, pedicle or vertebral hypogenesis at $\mathrm{C}-2$, and blocked and hypoplastic pedicles in KFS cases 
TABLE 2. Comparison of clinical outcomes between hybrid techniques and symmetric traditional techniques

\begin{tabular}{lccc}
\hline \multicolumn{1}{c}{ Variable } & Hybrid Group $(\mathrm{n}=21)$ & Control Group $(\mathrm{n}=82)$ & $\mathrm{p}$ Value \\
\hline Mean age \pm SD $(\mathrm{yrs})$ & $44.23 \pm 4.00$ & $44.85 \pm 1.64$ & 0.872 \\
\hline Males, no. $(\%)$ & $7(33.3)$ & $44(53.7)$ & 0.096 \\
\hline Mean surgical time \pm SD $(\mathrm{min})$ & $125.38 \pm 6.29$ & $119.41 \pm 3.77$ & 0.464 \\
\hline Mean blood loss \pm SD $(\mathrm{ml})$ & $208.1 \pm 19.30$ & $139.63 \pm 8.75$ & 0.001 \\
\hline Complications, no. $(\%)$ & $3(14.3)$ & $4(4.9)$ & 0.148 \\
\hline Mean JOA improvement rate \pm SD $(\%)^{*}$ & $61 \pm 7$ & $49 \pm 4$ & 0.161 \\
\hline Mean VAS neck pain score \pm SD & & $1.93 \pm 0.18$ & 0.572 \\
\hline Preop & $2.15 \pm 0.42$ & $2.64 \pm 0.16$ & 0.650 \\
\hline Postop 1 wk & $2.77 \pm 0.20$ & $1.39 \pm 0.19$ & 0.981 \\
\hline Postop 4 mos & $1.38 \pm 0.29$ & &
\end{tabular}

Boldface type indicates statistical significance.

* JOA improvement rate $=($ postoperative JOA - preoperative JOA $) /(17$ - preoperative JOA $) \times 100 \%$.

(Table 1). Eleven cases underwent atlantoaxial fixation. Among the 10 cases with occipitocervical fixation, 5 had fixation extending from the occiput to $\mathrm{C}-2$, while 4 cases with KFS extended the fixation to C-3, and 1 KFS case with a C2-6 congenital fusion had fixation extended to C-6. Skull traction (one-sixth of the body weight) was applied after the patient was under general anesthesia and administrated muscle relaxants. ${ }^{3}$ Three cases were irreducible AAD and required a transoral release followed by posterior fixation.

Among the 21 cases, there were no spinal cord or VA injuries experienced. The mean operative duration was 125 minutes and mean estimated blood loss was $208 \mathrm{ml}$ (Table 2). The average follow-up time was 45.0 months (range 36-60 months). Solid fusion was achieved in all cases by the 4-month follow-up (Tan criteria). Complete atlantoaxial reduction was achieved in 20 patients $(95.2 \%)$. Case 12 suffered from instrument loosening and recurrent dislocation, yet osseous fusion still occurred between the occiput and C-2. For the 18 cases with preoperative myelopathy, all cases experienced recovery in different degrees and the mean JOA score progressed from 13.5 to 15.5 .

In 21 hybrid cases, 3 (14.3\%) suffered complications. Case 1 had iliac wound drainage. Debridement was performed and was resolved after 3 weeks. Case 19 had CSF leakage during drilling of the occiput and was treated successfully by prolonged drainage and pressure dressing. Case 12 underwent C-2 PS and C-2 LS combined fixation and the atlantoaxial reduction was completed (Fig. 2). In the procedure, a strong cephalic stress on the C-2 screws was detected and additional halo vest supplemental fixation was used to reduce the stress on the combined instrumentation. This patient experienced significant recovery of his myelopathy during the 3 postoperative months but his condition subsequently deteriorated. The reconstructive CT scan at 4 months revealed the screws loosening and dislocation recurred, but solid osseous fusion occurred between the occiput and C-2. In the fifth month the transoral revision was performed and the odontoid was removed (Fig. 2G). His myelopathy recovered during the subsequent follow-up, superior to the preoperative situation. The failure of first instrumentation was from exces- sive superior odontoid migration and severe viscoelastic rebound force. The stress was mostly placed on the sole PS and resulted in pedicle osseous cutting. The combined and asymmetrical fixation device was clinically weaker than typical PS fixation, even with the supplemental strength of the halo vest. The lesson of this case is that for severe $\mathrm{AAD}$ and excessive superior odontoid migration, transoral release is recommended, especially for the cases treated with hybrid fixations.

In the 82 control cases, 4 patients suffered complications. One patient suffered incisional delayed healing (3 weeks), 1 suffered postoperative dysphagia for 6 months, 1 had severe occipital pain (lasting 3 months), and the last one had C-1 screw malposition and nonunion. For the last case, we carefully observed him for more than 2 years and the patient experienced good neurological recovery. Because the fixation was still rigid (as assessed by $\mathrm{CT}$ and dynamic radiography), we did not perform a revision.

The cases performed with hybrid techniques had a greater estimated blood loss than the control cases performed with symmetric traditional techniques $(\mathrm{p}=0.001$; Table 2). With regard to operative duration, complication rates, JOA improvement rates, and postoperative visual analog scale (VAS) neck pain scores, the cases performed using hybrid techniques showed no significant differences compared with the control cases.

\section{Illustrative Case}

This case (case 19) involved a 50-year-old woman with a 1-year history of progressive weakness and numbness of her lower extremities, and dysphagia. Neurological examination showed symmetrical hyperreflexia in the lower extremities. Hoffman and Babinski signs were present bilaterally. Limited range of motion of the cervical spine on both extension and flexion radiographs was observed. Radiographs demonstrated a reducible AAD, occipitalization of the atlas, and C2-3 congenital fusion (KFS). Reconstructive $\mathrm{CT}$ revealed that the left $\mathrm{C}-2$ pedicle was well developed (Fig. 3), while the right C-2 pedicle was invaded by the VA (Fig. 3D arrow). The fixation was extended to C-3 because of the C-2 and C-3 congenital fusion. On the 


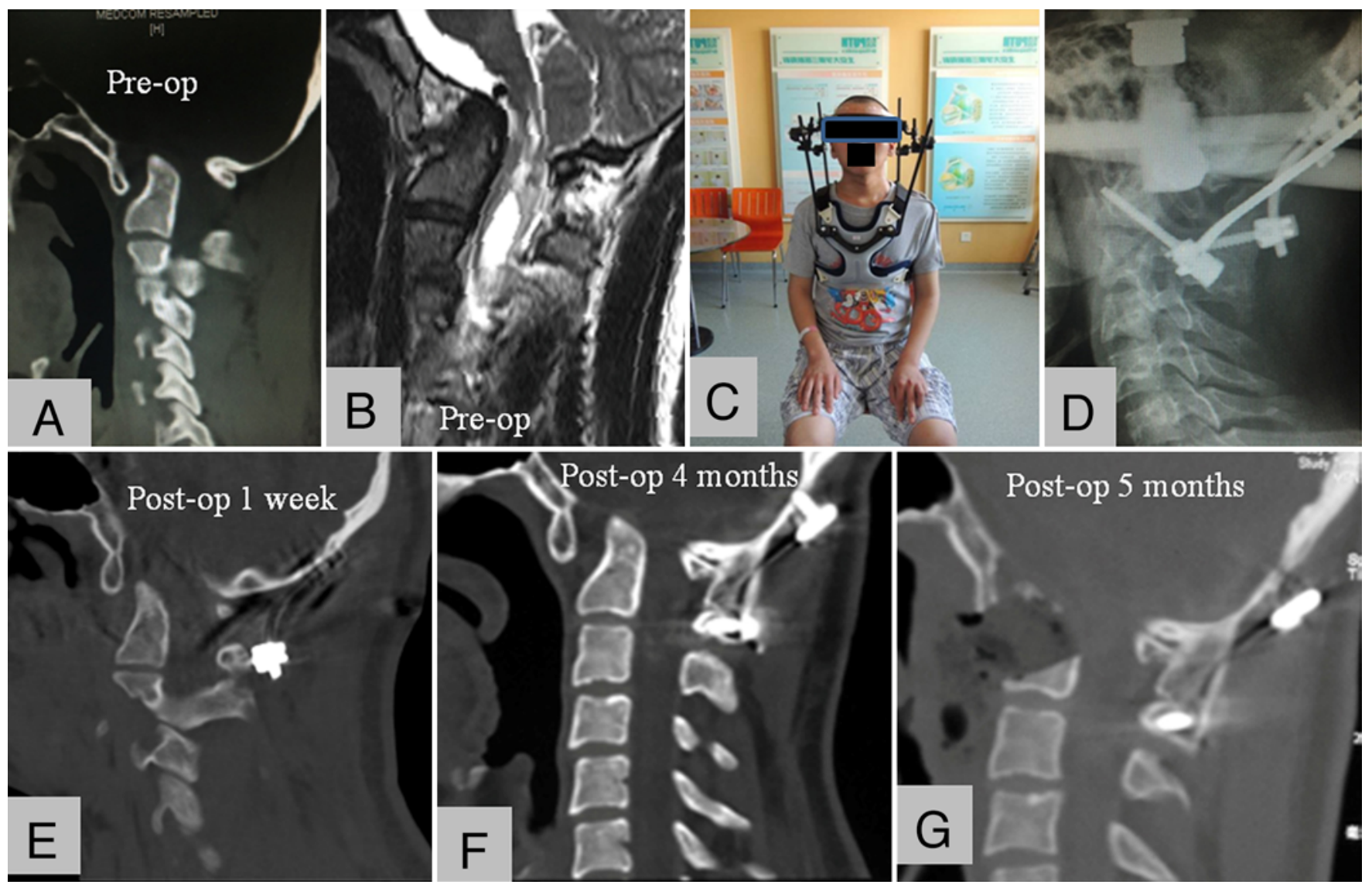

FIG. 2. Case 12. A: Preoperative CT revealed AAD, C-1 occipitalization, and severe superior odontoid migration. B: MR image showed severe ventral compression and syringomyelia. C: The patient underwent hybrid occipitocervical fixation strengthened by a halo vest. D: The fixation included a C-2 PS and C-2 LS (postoperative radiograph). E: CT at 1 week postoperatively confirmed obvious reduction of $A A D$ and superior odontoid migration. F: CT in the postoperative fourth month revealed that the dislocation recurred and there was solid osseous fusion. G: In the fifth postoperative month, a transoral odontoidectomy was performed to release ventral compression. Figure is available in color online only.

left side, C-2 PSs and C-3 LMSs were placed and connected with the occiput by a plate. Tightening of the cap on the C-2 screw achieved the atlantoaxial reduction. On the right side, a C-2 LS was used to avoid a VA injury. To strengthen the C-2 LS, a C-3 SPS was inserted and connected by a rod (Table 3). Morselized cancellous autograft harvested from the posterior iliac crest was bridged between the occiput and C-2 lamina. The postoperative CT scan showed complete reduction of the atlantoaxial joint, and the 4 used techniques were C-2 PS, C-2 LS, C-3 LMS, and C-3 SPS (Fig. 3H-K). The patient suffered postoperative CSF leakage (recognized during the drilling for occiput screws), which was treated successfully by prolonged drainage (72 hours) and pressure dressing. Postoperative CT (after 4 months) confirmed complete reduction and rigid fusion between the occiput and C-2. At the last follow-up at 2 years, the weakness of her lower extremities showed partial recovery (JOA score progressed from 14 to 16), and the dysphagia completely recovered.

\section{Discussion}

AAD treatment aims to stabilize the atlantoaxial joint with fixation and fusion without sacrificing the atlantooccipital and subaxial cervical joints. In the setting of occipitalization, fixation extending to the occiput does not additionally reduce the cervical collective movement; thus, fixation with extension to Oc-C2 fixation is universally recommended. ${ }^{1}$ For AAD with concomitant KFS (congenital cervical vertebra fusion), caudally extending the fixation to strengthen the instrument is reliable but should be kept within the congenitally fused segments..$^{16,17}$ In this report, fixation of all cases followed this principle. We have found that the screw-plate construct was fitted to reduce atlantoaxial displacement, especially for severe atlantoaxial anterior displacements..$^{13}$ Thus, C1-2 PS fixation was the first option, and a screw-plate construct was preferentially used. Even in the setting of osseous deformities of the pedicle, a unilateral PS and plate construct for atlantoaxial reduction and fixation was used to obtain optimal results.

In the setting of a high-riding VA at the $\mathrm{C}-2$ segment or hypogenesis of the C-2 pedicle (Table 3 ), the C-2 PS could not be inserted safely. To avoid VA injury, Wright described C-2 LSs in 2004, ${ }^{19}$ which have been widely used with favorable results. ${ }^{11}$ Because the axis of the C-2 LS 


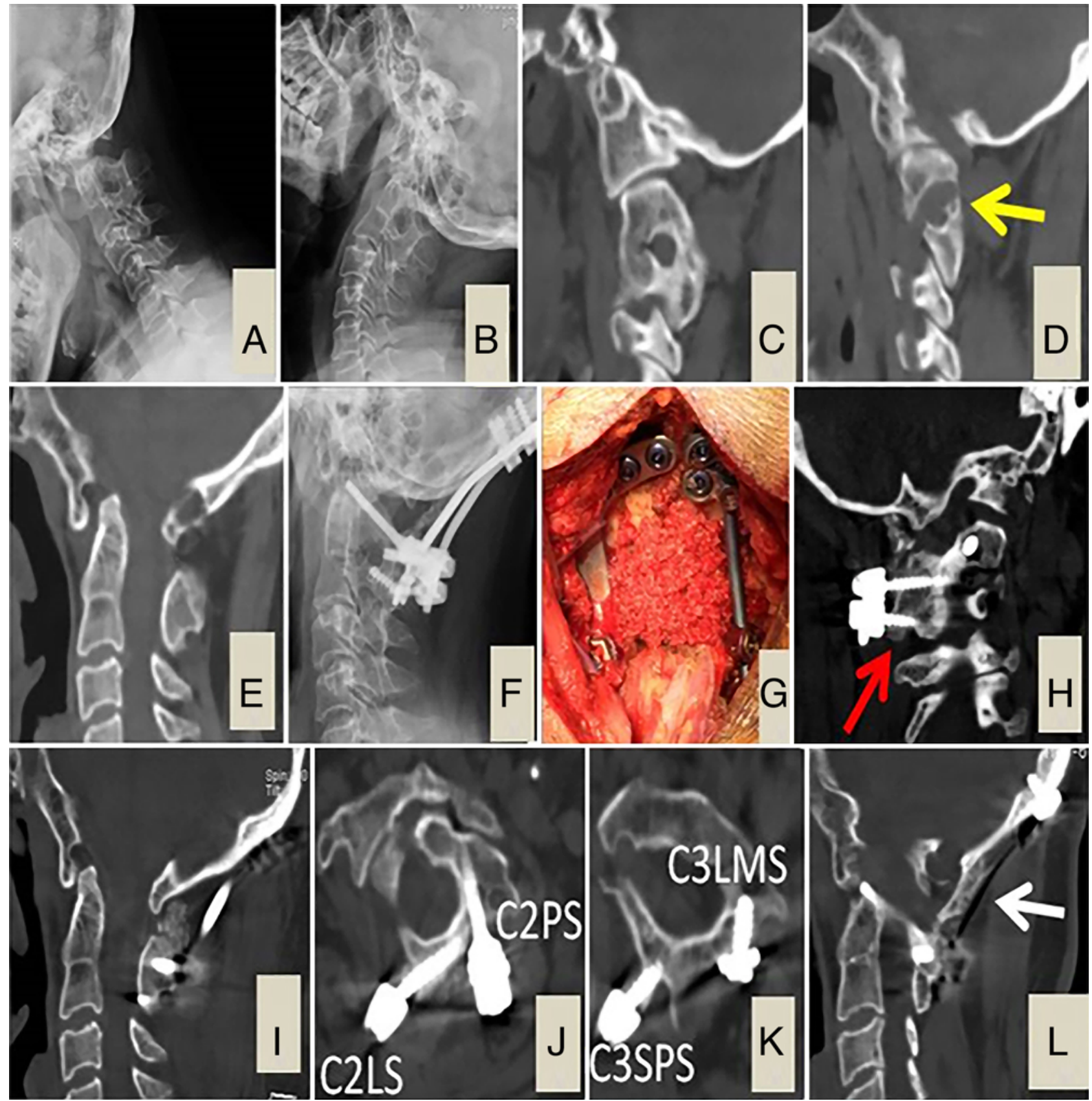

FIG. 3. Case 19. The dynamic radiographs of a 50-year-old woman showed reducible AAD, C-1 occipitalization, and C2-3 congenital fusion (A and B). Preoperative CT revealed the left C-2 pedicle could accommodate a 3.5-mm screw (C), while the right pedicle was occupied by the VA (D, arrow). The odontoid invaded the foramen magnum, and the ADI was abnormal (E). On the left side, C-2 PS and C-3 LMS were placed and connected with the occiput by a plate (F). On the right side, a C-2 LS and C-3 SPS were inserted and connected by a rod (F and G). Morselized cancellous grafts harvested from the posterior iliac crest were bridged between the occiput and C-2 lamina $(\mathrm{G})$. The postoperative parasagittal CT scan showed the C-2 LS and C-3 LMS $(\mathrm{H}$, arrow). The postoperative CT scan showed complete reduction of the atlantoaxial joint (I), and the 4 techniques included $\mathrm{C}-2$ PS, C-2 LS, C-3 LMS, and C-3 SPS (J and K). Postoperative CT (after 4 months) confirmed complete reduction and rigid fusion between the occiput and C-2 (L, arrow). Figure is available in color online only.

was different than that of the C-1 PS and the atlantoaxial displacement, we found the C-2 LS was a suboptimal anchor point for atlantoaxial reduction. We used unilateral PSs as a reductive anchor, and after the reduction, C-2 LSs were employed on the contralateral side to strengthen the fixation. Because of the large proportion of cancellous bone in the $\mathrm{C}-2$ spinous process and lamina, the $\mathrm{C} 1-2$ construct of the C-2 LS was less rigid than that of the C-2 PS. Lapsiwala et al. ${ }^{7}$ found that C1-2 fixation with C-2 LSs had less stiffness in resisting lateral bending. We found the construct of C-1 PS with C-2 LS could passably bear the stress of atlantoaxial reduction. However, the stiffness 
TABLE 3. Types of anatomical abnormalities and hybrid approaches in 21 hybrid cases

\begin{tabular}{ccc}
\hline $\begin{array}{c}\text { Categories of Anatomical } \\
\text { Abnormalities }\end{array}$ & $\begin{array}{c}\text { Salvage Techniques } \\
\text { (hybrid types) }\end{array}$ & $\begin{array}{c}\text { Cases } \\
(\mathrm{n}=21)\end{array}$ \\
\hline High-riding VA at C-2 segment & C-2 LS & 11 \\
\hline $\begin{array}{c}\text { Blocked \& hypoplastic C-2 } \\
\text { pedicles in KFS case }\end{array}$ & $\begin{array}{c}\text { C-2 LS (or w/ additional } \\
\text { C-3 and SPS) }\end{array}$ & 6 \\
\hline $\begin{array}{c}\text { Vertebral hypogenesis of C2-6 } \\
\text { \& C-2 PS plantation failure }\end{array}$ & $\begin{array}{c}\text { C-2 LS w/ halo vest (1 } \\
\text { case); C-2 LS w/ C-3 \& }\end{array}$ & 2 \\
\hline $\begin{array}{c}\text { C-5 SPS (another) } \\
\text { hypoplastic C-2 laminae w/ } \\
\text { hypotrophic pedicle of C-2 }\end{array}$ & C-3 LS w/ halo vest & 1 \\
\hline $\begin{array}{c}\text { Blocked \& hypoplastic C-2 } \\
\text { pedicles in KFS case, \& } \\
\text { high-riding VA at C-2 }\end{array}$ & C-2 LS w/ additional C-3 & 1 \\
\hline
\end{tabular}

of the occipitocervical fixation using C-2 LSs weakened, probably due to the longer lever arm and the occipitocervical rod possessing a more acute bend (from the failure of case 12). This hypothesis is supported by the work of Finn et al. ${ }^{3}$ Therefore, for KFS patients with the occipitocervical fixation using C-2 LS fixation, we recommend extending the fixation to $\mathrm{C}-3$ and using additional halo vest stabilization.

In this report, the subaxial LMS and SPS were short $(12-14 \mathrm{~mm})$ and were performed as supplements to the PS or LS. The PS was easily connected with the LMS, while the LS connected with the SPS (Fig. 3). For patients with KFS, extending fixation to the congenital fused segment will not sacrifice the lower cervical movements. In this report, 3 SPSs were used in 2 patients (at C-3 and C-5, respectively). Shin et al. evaluated the anatomical feasibility of LS placement in C3-7 using 3D screw trajectory software and found few patients could accommodate subaxial LS $(13.5 \%$ at C-3, $1.9 \%$ at C- $4,0.9 \%$ at C-5, and $8.8 \%$ at C-6).$^{10}$ Thus, the SPSs at the subaxial cervical spine were used to strengthen C-2 LSs.

\section{Limitations of the Study}

We acknowledge several limitations to this study. First, the fact that the operating surgeon was one of two surgeons performing the clinical assessment and determining fusion status could potentially introduce bias into the results. However, these results still support the usage of alternative fixation techniques using the largest series to date of patients with AAD. Future investigations with blinded fusion assessment could help confirm the results presented here. In addition, follow-up duration remains limited at 45 months and further long-term follow-up data are required to assess the feasibility of the hybrid techniques.

\section{Conclusions}

The result of this largest series to date concerning usage of alternative fixation techniques in the setting of osseous or vascular deformities shows hybrid salvage fixation is a reasonable and favorable option for treatment of AAD. However, asymmetrical hybrid fixation is only recommended as a salvage technique because the fixation is significantly less robust than traditional techniques. In cases of severe atlantoaxial displacement or excessive superior odontoid migration, even though the reduction can be achieved, the weaker hybrid fixation experiences additional stress and may compromise outcomes. Thus, the excessive stress loading on the fixation needs to be considered. The performance of a transoral release as well as the addition of a halo vest is recommended to decrease the loading on the construct.

\section{Acknowledgments}

Chinese Capital Medical Developmental funding was received for this project (Youth project grant no. 2014-4-4097).

\section{References}

1. Abumi K, Takada T, Shono Y, Kaneda K, Fujiya M: Posterior occipitocervical reconstruction using cervical pedicle screws and plate-rod systems. Spine (Phila Pa 1976) 24:1425-1434, 1999

2. Du S, Ni B, Lu X, Xie N, Guo X, Guo Q, et al: Application of unilateral $C 2$ translaminar screw in the treatment for atlantoaxial instability as an alternative or salvage of pedicle screw fixation. World Neurosurg 97:86-92, 2017

3. Finn MA, Fassett DR, Mccall TD, Clark R, Dailey AT, Brodke DS: The cervical end of an occipitocervical fusion: a biomechanical evaluation of 3 constructs. Laboratory investigation. J Neurosurg Spine 9:296-300, 2008

4. Goel A, Kulkarni AG: Mobile and reducible atlantoaxial dislocation in presence of occipitalized atlas: report on treatment of eight cases by direct lateral mass plate and screw fixation. Spine (Phila Pa 1976) 29:E520-E523, 2004

5. Harms J, Melcher RP: Posterior C1-C2 fusion with polyaxial screw and rod fixation. Spine (Phila Pa 1976) 26:2467-2471, 2001

6. Kang DG, Lehman RA Jr, Wagner SC, Peters C, Riew KD: outcomes following arthrodesis for atlanto-axial osteoarthritis. Spine (Phila Pa 1976) 42:E294-E303, 2017

7. Lapsiwala SB, Anderson PA, Oza A, Resnick DK: Biomechanical comparison of four $\mathrm{C} 1$ to $\mathrm{C} 2$ rigid fixative techniques: anterior transarticular, posterior transarticular, $\mathrm{C} 1$ to $\mathrm{C} 2$ pedicle, and $\mathrm{C} 1$ to $\mathrm{C} 2$ intralaminar screws. Neurosurgery 58:516-521, 2006

8. Menezes AH: Craniovertebral junction database analysis: incidence, classification, presentation, and treatment algorithms. Childs Nerv Syst 24:1101-1108, 2008

9. Miyakoshi N, Hongo M, Kobayashi T, Suzuki T, Abe E, Shimada Y: Comparison between bilateral $\mathrm{C} 2$ pedicle screwing and unilateral $\mathrm{C} 2$ pedicle screwing, combined with contralateral C2 laminar screwing, for atlantoaxial posterior fixation. Asian Spine J 8:777-785, 2014

10. Shin SI, Yeom JS, Kim HJ, Chang BS, Lee CK, Riew KD: The feasibility of laminar screw placement in the subaxial spine: analysis using 215 three-dimensional computed tomography scans and simulation software. Spine J 12:577584,2012

11. Sinha S, Jagetia A, Aher RB, Butte MK: Occiput/C1-C2 fixations using intra-laminar screw of axis-a long-term follow-up. Br J Neurosurg 29:260-264, 2015

12. Tan GH, Goss BG, Thorpe PJ, Williams RP: CT-based classification of long spinal allograft fusion. Eur Spine J 16:18751881,2007

13. Visocchi M, Pietrini D, Tufo T, Fernandez E, Di Rocco C: Pre-operative irreducible $\mathrm{C} 1-\mathrm{C} 2$ dislocations: intra-operative reduction and posterior fixation. The "always posterior strategy". Acta Neurochir (Wien) 151:551-560, 2009

14. Wang C, Wang SL, Yan M: [C(2) trans-laminar screws for atlantoaxial instability: preliminary clinical report of nine 
cases.] Zhonghua Wai Ke Za Zhi 46:1557-1561, 2008 (Chinese)

15. Wang C, Yan M, Zhou H, Wang S, Dang G: Atlantoaxial transarticular screw fixation with morselized autograft and without additional internal fixation: technical description and report of 57 cases. Spine (Phila Pa 1976) 32:643-646, 2007

16. Wang S, Wang C, Leng H, Zhao W, Yan M, Zhou H: Cablestrengthened $\mathrm{C} 2$ pedicle screw fixation in the treatment of congenital C2-3 fusion, atlas occipitalization, and atlantoaxial dislocation. Neurosurgery 71:976-984, 2012

17. Wang S, Wang C, Leng H, Zhao W, Yan M, Zhou H: Pedicle screw combined with lateral mass screw fixation in the treatment of basilar invagination and congenital C2-3 fusion. $\mathbf{J}$ Spinal Disord Tech [epub ahead of print], 2013

18. Wang S, Wang C, Yan M, Zhou H, Dang G: Novel surgical classification and treatment strategy for atlantoaxial dislocations. Spine (Phila Pa 1976) 38:E1348-E1356, 2013

19. Wright NM: Posterior C2 fixation using bilateral, crossing C2 laminar screws: case series and technical note. J Spinal Disord Tech 17:158-162, 2004

20. Yang SY, Boniello AJ, Poorman CE, Chang AL, Wang S,
Passias PG: A review of the diagnosis and treatment of atlantoaxial dislocations. Global Spine J 4:197-210, 2014

\section{Disclosures}

Dr. Passias reports being a consultant to Medicrea and SpineWave, receiving speaking/teaching arrangements from Zimmer-Biomet, and a grant from CSRS.

\section{Author Contributions}

Conception and design: Wang, Passias. Acquisition of data: Wang, Passias. Analysis and interpretation of data: Wang, Tian, Diebo, Passias. Drafting the article: Wang, Tian, Diebo, Passias. Critically revising the article: all authors. Reviewed submitted version of manuscript: all authors.

\section{Correspondence}

Shenglin Wang: Peking University Third Hospital, Beijing, China. pkuwsl@126.com. 